\title{
Characteristics of internal oblique muscle activity during walking in healthy and patients with hip osteoarthritis
}

Kazuya Okazawa ${ }^{*}$ and Hiroshi Katoh ${ }^{2}$

*Correspondence: okazawa@reha.med.kyushu-u.ac.jp

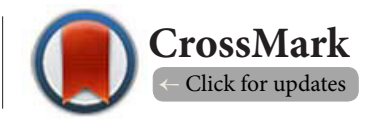

'Department of Rehabilitation, Kyushu University Hospital, Japan.

${ }^{2}$ Kyushu University of Nursing and Social welfare Graduate School, Japan.

\begin{abstract}
Background and purpose: In a clinical setting, patients with hip osteoarthritis often complain of trunk instability during the gait, therefore, this study aims to determine the characteristics of left and right internal oblique muscle activities during walking in healthy individuals and patients with hip osteoarthritis $(\mathrm{OA})$.

Methods: Participants included 17 healthy males and 10 (2 males and 8 female) with hip OA. The characteristics of muscle activity in one walking cycle were compared using integrated EMG analysis (\% IEMG) and co-contraction index (CCI), which is an index of simultaneous muscles.

Results: The \%IEMG and CCI values were greater and less, respectively, in patients with hip OA than in healthy individuals.

Conclusion: It is important to increase the $\mathrm{CCI}$ of the left and right internal oblique muscles to improve the trunk stability during walking in patients with hip OA.
\end{abstract}

Keywords: Inner oblique muscle, Hip osteoarthritis, Co-contraction index

\section{Introduction}

The prevalence rate of hip osteoarthritis in Japan is $1.0 \%-4.3 \%$ [1], and the number of patients is estimated to be 1.2-5.1 million. The age of onset is usually $40-50$ years, and hip osteoarthritis is considered one of the representative diseases of the hip joint [2]. In hip osteoarthritis, X-ray images often show sclerosis of the sacroiliac joint $[3,4]$, accounting for about $26 \%$ of the cases of back pain [5]. In addition, it has been reported that about $20 \%$ of patients with osteoarthritis associated with sacroiliac joint pain have sacroiliac joint instability [6]. Thus, hip pain and back pain are closely related and are important characteristics of hip-spine syndrome [7]. From this background, it is increasingly important to adopt a whole-body perspective, in addition to a local perspective, when evaluating and implementing physical therapy in motor disease [8]. Particularly, slight movement of the trunk, which accounts for approximately one-half of the total bodyweight, can have a significant influence on the whole-body balance. Additionally, the trunk is an important foundation, from which the limbs function, and it provides static stability such as attitude retention, and dynamic stability required to perform various motions [9]. Snijders [10] reported that the internal oblique muscle, which is located in the trunk, relieves the shear loading force of the sacroiliac joint, and contributes to stabilization of the pelvis. The pelvic stabilization is further supported by co-contraction of the agonist and antagonist muscles (ie, the right and left internal oblique muscles). However, excessive co-contraction may hinder joint motion, resulting in inefficient muscle function and increased energy consumption during exercise [11]. Conversely, low co-contraction may destabilize the joint, decreasing the supply of biomechanical force, which protects the joint [12]. Over time, this may contribute to problems, such as sacroiliac joint or low back pain. In the present study, surface electromyogram (EMG) analysis was used to determine the muscle activity and co-contraction index (CCl) of the right and left internal oblique muscles during walking in healthy individuals and patients with hip osteoarthritis (OA).

\section{Methods \\ Participants}

The participants included in this study were 17 healthy students 
enrolled at Kyushu University of Nursing and Welfare, and 10 in-patients who were diagnosed with unilateral hip OA, hospitalized for physical therapy. Exclusion criterion for healthy participants was hospital visit for treatment within the past year. Exclusion criteria for patients were individuals diagnosed with an orthopedic disease other than OA, a central nervous system disorder, and respiratory or cardiovascular disease within the past year. The characteristics of included patients are shown in Table 1. The research protocol was reviewed and approved by the Kyushu University of Nursing and Social Welfare and the Fukuoka Wajiro Hospital ethics committees (approval number: 26-019, 27-20). In addition, all patients were completely informed of the relevance and purpose of the research, and they provided consent prior to participation.

Table 1. Physical characteristic of participants.

\begin{tabular}{|c|c|c|c|c|c|}
\hline \multicolumn{4}{|c|}{ Healthy $(n=17)$} & \multicolumn{2}{|c|}{ hip OA $(n=10)$} \\
\hline Gender (Male/Female) & 17 & 1 & 0 & 2 & 8 \\
\hline Affected side (left / right) & & - & & 6 & I \\
\hline Age(year) & 19.1 & \pm & 0.7 & 64.2 & 9.7 \\
\hline Height $(\mathrm{cm})$ & 170.3 & \pm & 10.7 & 163.2 & \pm 49.0 \\
\hline Weight (kg) & 68.4 & \pm & 10.7 & 53.0 & \pm 10.1 \\
\hline $\mathrm{BMI}\left(\mathrm{kg} / \mathrm{m}^{2}\right)$ & 23.7 & \pm & 7.7 & 19.3 & 6.8 \\
\hline JOA score & & - & & 80.9 & \pm 12.8 \\
\hline $\mathrm{K} / \mathrm{L}$ score & & - & & $\mathrm{I}: 3, \mathrm{II}$ & $: 4$, III $: 3$ \\
\hline
\end{tabular}

BMI: body mass index

K/L score: KellorenLawrence grade

\section{Gait collection}

An EMG signal was obtained from the left and right internal oblique muscles using the blue sensor (P-00-S; Medicotest Inc., Denmark) disposable electrodes. In accordance with a previous study [13], the electrode attachments were positioned 2 $\mathrm{cm}$ inside and below the Anterior superior iliac spine (ASIS). Following appropriate skin preparation, to reduce impedance, the electrodes were placed 30-mm apart (measured from their centers) on the muscle belly. Moreover, an earth electrode was attached to the ASIS.

Next, pressure sensors (Tekscan Inc., USA) were attached to the heel of individuals to identify one walking cycle. Specifically, a thin piezoelectric sensor with a sensitivity of $2 \mathrm{~kg}$ was used to identify one walking cycle. The piezoelectric element sensor was affixed to the participant's heel, and the participant was allowed to walk. The point when the piezoelectric element sensor voltage was $30 \mathrm{mV}$ was considered as heel contact.

\section{Data analysis}

The EMG Master (Mediarea support Inc., Japan) surface electrometer was used to measure the muscle activity using a sampling frequency of $1 \mathrm{kHz}$. The maximum voluntary contraction (MVC) of the left and right internal oblique muscles was measured over 3 seconds, and the middle 2 seconds of data were used for analyses [14]. Measurements were obtained during 10-m of free walking four times, which did not include any special instructions. All EMG signals were filtered using a high-pass Butterworth filter with a cutoff frequency of $15 \mathrm{~Hz}$ to remove motion artifacts. After that, following full-wave rectification processing by spreadsheet software excel (Microsoft Inc., USA), integrated EMG (IEMG) analysis was performed with this software. The stride time on one side was the time from when the heel touched the floor to when the same heel touched the floor again. The stride times for all trials were normalized to a $100 \%$ gait cycle to allow direct comparisons across different speeds. The IEMG was processed with normalized data. Five gait cycles were randomly selected from four times walks per subject, and the IEMGs during gait were divided by the muscle activity of MVC, and normalized (\%IEMG). The \%IEMG at $5 \%$ interval of the walking cycle was calculated. Moreover, the mean \%IEMG over one walking cycle was calculated from the obtained \%IEMG, and the muscle activities of healthy individuals and patients with hip OA were compared. To evaluate the simultaneous contraction of the left and right internal oblique muscles during walking, the $\mathrm{CCl}$ was calculated using the method described by Falconer et al [15] (Figure 1).

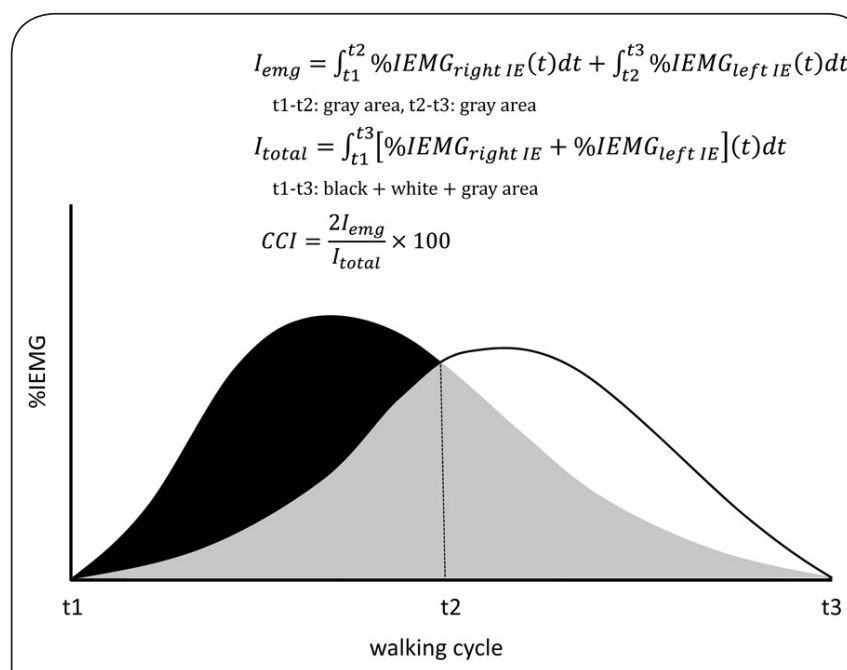

Figure 1. Co-contraction index (CCI).

The black area indicates the right internal oblique muscle (right IE), and the white area indicates the left internal oblique muscle (left IE). The gray area indicates overlapping of the two lines, indicating simultaneous contraction.

CCI was calculated as follows; $\mathrm{CCI}=2$ gray $/($ black + white +2 gray).

\section{Statistical analyses}

Statistical analyses were performed using IBM SPSS statistics software version 23 (IBM Inc., Japan). The \%IEMG and CCI were assessed using Tukey's test for multiple comparisons after confirming normal distribution of data using Shapiro-Wilk test. Statistical significance was defined as a $p$-value of $<0.05$.

\section{Results}

In healthy individuals, the right internal oblique muscle activity 
was $13.2 \pm 8.2 \%$ at $50 \%$ of the walking cycle, which was significantly greater than the value of $7.0 \%$ obtained at $100 \%$ of the walking cycle. The left internal oblique muscle activity was $13.5 \pm 6.0 \%$ and $13.4 \pm 7.4 \%$ at $40 \%$ and $50 \%$ of the walking cycle, respectively. These values were significantly greater than the values of $7.3 \pm 4.4 \%$ obtained at $100 \%$ of the walking cycle $(p<0.05)$ (Figure 2). In patients with unilateral hip $O A$, there were no significant differences in left or right internal oblique muscle activity values measured during all phase of the walking cycle. The right and left internal oblique muscle activity levels during all phases of the walking cycle were, respectively, $9.7 \pm 1.7 \%$ and $12.7 \pm 2.3 \%$ among healthy individuals, $38.2 \pm 6.2 \%$ and $49.1 \pm 10.6 \%$ among patients with right hip $O A$, and $56.2 \pm 21.5 \%$ and $89.4 \pm 20.8 \%$ among those with left hip $\mathrm{OA}$; the values for patients with left or right hip $O A$ were significantly greater than in healthy individuals $(p<0.01$; Table 2).

The $\mathrm{CCl}$ of the internal oblique muscles during walking was $80.1 \pm 7.5 \%$ among healthy individuals, $65.7 \pm 10.4 \%$ among patients with right $\mathrm{OA}$, and $63.4 \pm 14.8 \%$ among those with left $\mathrm{OA}$. The $\mathrm{CCl}$ of healthy individuals was significantly greater than that of patients with either right or left hip $\mathrm{OA}$ $(p<0.01 ;$ Table 3$)$.

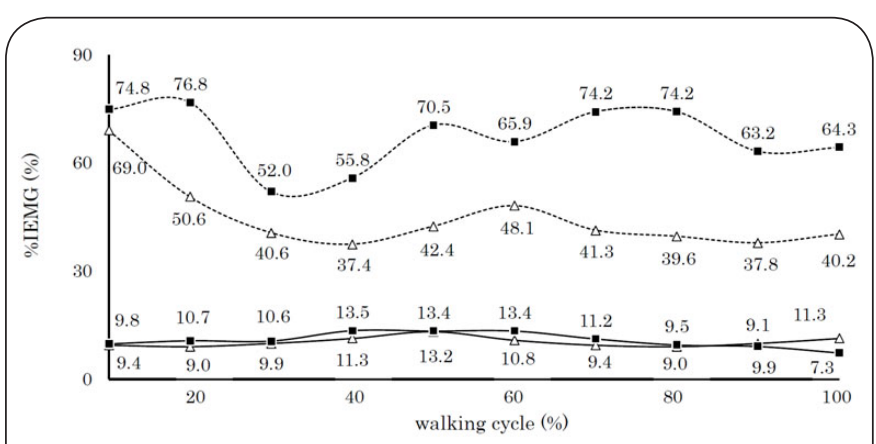

Figure 2.\%IEMG during of the walking cycle.

Straight line is shown healthy subject. Dashed line is shown patients with hip OA. Triangle is shown right internal oblique muscle. Square is shown left internal oblique muscle.

Table 2. \%IEMG during all phases of the walking cycle.

\begin{tabular}{lccc}
\hline & healthy & right hip OA & left hip OA \\
\hline $\begin{array}{l}\text { right internal oblique } \\
\text { muscle (\%IEMG) }\end{array}$ & $9.7 \pm 1.7$ & $38.2 \pm 6.2^{* *}$ & $56.2 \pm 21.5^{* * *}$ \\
$\begin{array}{l}\text { left internal oblique } \\
\text { muscle (\%IEMG) }\end{array}$ & $12.7 \pm 2.3$ & $49.1 \pm 10.6^{* *}$ & $89.4 \pm 20.8^{* *}$ \\
\hline
\end{tabular}

$* *$ : healty VS right or leflt $\mathrm{OA}, \mathrm{p}<0.01$, mean $\pm \mathrm{SD}$.

Table 3. CCI in the internal oblique muscles.

\begin{tabular}{cccc}
\hline & healthy & right OA & left OA \\
\hline CCI(\%) & $80.1 \pm 7.2$ & $65.7 \pm 10.4 *$ & $63.4 \pm 14.8^{*}$ \\
\hline
\end{tabular}

*: healty VS right or leflt $\mathrm{OA}, \mathrm{p}<0.05$, mean $\pm \mathrm{SD}$

\section{Discussion}

When performing physical therapy for osteoarthritis patients in a clinical setting, it is important to evaluate and treat from a whole-body as well as a local perspective. Among them, the trunk exists at the center of the body and is an important part that becomes the basis of movement. The spine that constitutes the trunk and the hip joint, which is the adjacent joint, are closely related, and one pathology affects the other pathology [7]. But the functional characteristics of the trunk of patients with hip OA are still unclear. Therefore, in the present study, the EMG analysis were used to determine the muscle activity and $\mathrm{CCl}$ of the right and left internal oblique muscles during walking in healthy individuals and patients with hip osteoarthritis.

The results of this study demonstrated greater activity in the left and right oblique muscles in healthy individuals during $50 \%$ of the walking cycle phase. This corresponds with the right lower-limb Terminal stance (TSt), a subphase of one walking cycle, in the Rancho Los Amigos walking classification [16], demonstrating the greatest pelvic rotation angle. There were no significant differences in the activities of the left and right internal oblique muscles during each phase of the walking cycle in patients with hip OA; however, their muscle activity levels were significantly greater than those of healthy individuals. Furthermore, in line with this finding, Crawford et al. [17] reported no age difference in the peak activity of the internal oblique muscles during walking in healthy adults. Therefore, the result of this study may be unique to hip OA patients.

Consequently, we considered $\mathrm{CCl}$. The present results demonstrated that the $\mathrm{CCl}$ of patients with hip OA was significantly less than that of healthy individuals. This muscular activity during one gait cycle may not be consistent with $\mathrm{CCl}$ shown in the previous study, but there is no doubt that the co-contraction functions of at least the left and right internal oblique muscles were reduced. A previous study has reported that the muscle activity time of the internal oblique muscle is prolonged [17], and the $\mathrm{CCl}$ of the back-extensor muscles is increased during walking in healthy elderly individuals [18]. Considering these reports, this study showed that the $\mathrm{CCl}$ of elderly patients with hip OA was less than, indicating the opposite characteristics to those in healthy elderly individuals. If the $\mathrm{CCl}$ is too large, smooth movement is impaired, and if the $\mathrm{CCl}$ is too small, joint stability decreases. Therefore, it was suggested that patients with hip OA were unable to maintain adequate $\mathrm{CCl}$ of the internal oblique muscles, and the trunk was stabilized by increasing the \%IEMG.

This study aimed to compare the muscular activity characteristics of the internal oblique muscles during walking in patients with hip osteoarthritis and healthy individuals. There was a characteristic difference between the two groups. However, the mean age of the healthy individuals was low and the effects of age could not be excluded. In addition, the sex of the patients with hip osteoarthritis could not be unified 
Okazawa et al, Physical Therapy and Rehabilitation 2019,

http://www.hoajonline.com/journals/pdf/2055-2386-6-13.pdf

doi: $10.7243 / 2055-2386-6-13$

because of limited clinical data collection. In the future, it will be necessary to conduct joint research at multiple institutions, increase the amount of data, and perform a comparative study that considers age and sex.

\section{Competing interests}

The authors declare that they have no competing interests.

Authors' contributions

\begin{tabular}{|l|c|c|}
\hline Authors' contributions & KO & HK \\
\hline Research concept and design & $\checkmark$ & $\checkmark$ \\
\hline Collection and/or assembly of data & $\checkmark$ & -- \\
\hline Data analysis and interpretation & $\checkmark$ & $\checkmark$ \\
\hline Writing the article & $\checkmark$ & $\checkmark$ \\
\hline Critical revision of the article & $\checkmark$ & $\checkmark$ \\
\hline Final approval of article & $\checkmark$ & $\checkmark$ \\
\hline Statistical analysis & $\checkmark$ & -- \\
\hline
\end{tabular}

\section{Acknowledgment}

The author would like to thank Professor Hiroshi Kato for his guidance on this research. I would also like to thank Mr. Koichi Moriguchi, Kiyotaka Hada, and Takeshi Shimamura from Kato Lab, the research advice. Finally, thanks to the referee for the helpful comments.

\section{Publication history}

Editor: Gordon John Alderink, Grand Valley State University, USA. Received: 26-July-2019 Final Revised: 23-Sept-2019

Accepted: 26-Oct-2019 Published: 12-Nov-2019

\section{References}

1. Yoshimura N, Campbell L, Hashimoto T, Kinoshita H, Okayasu T, Wilman C, Coggon D, Croft P and Cooper C. Acetabular dysplasia and hip osteoarthritis in Britain and Japan. BrJ Rheumatol. 1998; 37:1193-7. | Article | PubMed

2. Jingushi S, Ohfuji $S$ and Sofue $M$ et al. Multiinstitutional epidemiological study regarding osteoarthritis of the hip in Japan. J Orthop Sci. 2010; 15: 626-631.

3. Ogawara $M$, Sugimori $T$ and Nishino $M$ et al. Osteosclerosis of sacro-iliac joint in osteoarthritis of the hip. Hip joint. 2002; 28: 51-53.

4. Watelain E, Dujardin F, Babier F, Dubois D and Allard P. Pelvic and lower limb compensatory actions of subjects in an early stage of hip osteoarthritis. Arch Phys Med Rehabil. 2001; 82:1705-11. | Article | PubMed

5. Chosa E, Sakamoto T and Watanabe $S$ et al. Hip-spine syndrome classification based on clinical and radiological findings. Journal of Joint Surgery. 2004; 23:476-483.

6. Saito $A$, Kikuchi $S$ and Yabuki S et al. The influence of the coxarthrosis to the sacroiliac joint. Clinical Orthopaedic Surgery. 2002; 37:231-236.

7. Offierski CM and MacNab I. Hip-spine syndrome. Spine (Phila Pa 1976). 1983; 8:316-21. | Article | PubMed

8. de Luca K, Pollard H, Brantingham J, Globe G and Cassa T. A randomized controlled trial of chiropractic management of the lower limb kinetic chain for the treatment of hip osteoarthritis: a study protocol. J Chiropr Med. 2011; 10:86-92. | Article | PubMed Abstract | PubMed FullText

9. Klein-Vogelbach S. Fundamental observation criteria, Functional kinetics. 1990; 74-143.

10. Snijders CJ, Ribbers MT, de Bakker HV, Stoeckart R and Stam HJ. EMG recordings of abdominal and back muscles in various standing postures: validation of a biomechanical model on sacroiliac joint stability. $J$ Electromyogr Kinesiol. 1998; 8:205-14. | Article | PubMed

11. Manchester D, Woollacott M, Zederbauer-Hylton N and Marin O. Visual, vestibular and somatosensory contributions to balance control in the older adult. J Gerontol. 1989; 44:M118-27. | Article | PubMed

12. Damiano DL. Reviewing muscle cocontraction: Is it a developmental, pathological, or motor control issue? Phys Occup Ther Pediatr. 1993; 12:3-20.

13. Ng JK, Kippers $V$ and Richardson CA. Muscle fibre orientation of abdominal muscles and suggested surface EMG electrode positions. Electromyogr Clin Neurophysiol. 1998; 38:51-8. | PubMed

14. Vera-Garcia FJ, Moreside JM and McGill SM. MVC techniques to normalize trunk muscle EMG in healthy women. J Electromyogr Kinesiol. 2010; 20:10-6. | Article | PubMed

15. Falconer $\mathrm{K}$ and Winter DA. Quantitative assessment of co-contraction at the ankle joint in walking. Electromyogr Clin Neurophysiol. 1985; 25:13549. | PubMed

16. Perry J and Burnfield JM. Gait analysis: Normal and pathological function, second ed. 2010; 4-16.

17. Crawford R, Gizzi L, Dieterich A, Ni Mhuiris A and Falla D. Age-related changes in trunk muscle activity and spinal and lower limb kinematics during gait. PLoS One. 2018; 13:e0206514. | Article | PubMed Abstract | PubMed FullText

18. Lee HJ, Chang WH, Hwang SH, Choi BO, Ryu GH and Kim YH. Age-Related Locomotion Characteristics in Association with Balance Function in Young, Middle-Aged, and Older Adults. J Aging Phys Act. 2017; 25:247253. | Article | PubMed

\section{Citation:}

Okazawa $\mathrm{K}$ and Katoh H. Characteristics of internal oblique muscle activity during walking in healthy and patients with hip osteoarthritis. Phys Ther Rehabil. 2019; 6:13. http://dx.doi.org/10.7243/2055-2386-6-13 